\title{
Antiretroviral Treatment in Correctional Facilities
}

\author{
Emanuele Pontali, MD \\ Health Services, Prison of Genoa, Genoa, Italy
}

\begin{abstract}
Purpose: To identify and describe the relevant issues and difficulties associated with provision of antiretroviral therapy in correctional facilities. Method: We performed a review and analysis of currently available literature and experiences on antiretroviral treatment (ART) in the prison setting. Results: Antiretroviral therapy is administered to human immunodeficiency virus (HIV)-infected prison inmates in many countries. Numerous issues have been identified and discussed; among the most relevant are availability of basic and specific HIV care, prisons as entry point for HIV care for marginalized populations, policy and guidelines for ART, specialized HIV care in prison, modality of administration of ART, adherence to ART, and continuity of care between prison and community. Conclusion: Antiretroviral treatment is a feasible intervention in the context of correctional facilities. To ensure full benefit of ART for those prisoners in need, in each country there should be plans for ART provision in correctional facilities and the necessary arrangements should be made to ensure ART administration and optimal adherence to it. Key words: antiretroviral therapy, HIV, prison
\end{abstract}

$\mathbf{P}$ rovision of specific care for people living with human immunodeficiency virus (HIV) infection or acquired immunodeficiency syndrome (AIDS) has become a priority worldwide, and it is considered to be a basic human right. The right to medical care also includes the provision of antiretroviral therapy (ART) in the context of comprehensive HIV / AIDS care.

Combination ART, and in particular highly active antiretroviral therapy (HAART), has proven to be effective in obtaining maximal and durable suppression of HIV viral load, restoration and preservation of immunologic function, improvement of quality of life, and reduction of HIV-related morbidity and mortality. ${ }^{1-5}$ These results can be observed even in "difficult" HIV-infected populations (injection drug users, homeless people, ethnic minorities, and others) ${ }^{6-10}$ and in "difficult" contexts such as developing countries. ${ }^{11,12}$

Providing access to ART for those in need in the context of correctional facilities is a challenge, but it can be feasible following the existing national and/ or international guidelines for HIV / AIDS care and ART use.

\section{DEFINING THE SETTING}

Correctional facilities include jails and prisons. Jails are usually defined as facilities housing accused persons awaiting trial or convicted criminals serving short sentences (e.g., sentences of up to 1 year), while prisons are defined as facilities housing convicted inmates for longer sentences. In some countries, this distinction does not exist and the same facilities house all kind of prisoners; in other countries, different names are used for a variety of detention facilities. For the sake of simplicity, when referring to the same generic detention facilities, only the terms prison or correctional facility will be used in the text.

In most countries, minority populations, which are overrepresented in the inmate population, are the ones that are hardest hit by HIV and tend to

For correspondence or reprints contact: Dr. Emanuele Pontali; Prison of Genoa; Piazzale Marassi, 2; 16142 Genova, Italy. Email: pontals@yahoo.com

HIV Clin Trials 2005;6(1):25-37

(C) 2005 Thomas Land Publishers, Inc. www.thomasland.com 
have disproportionately less access to health care in the outside community. Prisoners most often come from disadvantaged and marginalized social groups, such as the urban poor, ethnic minorities, recent immigrants, and injecting drug users (IDUs). Malnutrition, unhealthy living conditions, and lack of access to basic medical care are common to these groups.

HIV infection and AIDS have hit the prison systems of all countries. Frequently, HIV prevalence among prisoners is higher than in the general population, and many of those who carry HIV infection in prison were already infected when they were outside prison. ${ }^{13}$ In 1995 , about $13 \%$ of the prison population in Italy, $15 \%$ of prisoners of Porto prison (Portugal), and more than $10 \%$ of prisoners in Santa Fe province (Argentina) were reported to be HIV-infected (HIV+). In Italy at year end 2001 and 2002, HIV prevalence had decreased at $2.6 \%$ and $2.2 \%$ of prison population, respectively; in 2002, it was still at $8.1 \%$ among IDU prisoners. $^{14,15}$ In French prisons, HIV prevalence was estimated to be 10 times higher than that of the general population in 1997 and to be 2\% (1\%-4\%) among Irish prisoners in $1999 .{ }^{16}$ In the United States, HIV hit correctional facilities early and hit them hard; nationwide prevalence of HIV infection among inmates was 3.5\% among women and 2.2\% among men (opposite proportions than in the general population) in 1999 and racial and ethnic minorities were also disproportionately affected. ${ }^{17}$ At year end 2001, 3.2\% of all female state prison inmates were HIV+ compared to $2.0 \%$ of males. ${ }^{18}$ Nationwide, in 1999, the rate of reported AIDS cases among incarcerated persons was 5 times the rate for the general population in the United States (3 times in 2001). ${ }^{17,18}$ A 2001 report from Brazilian prisons showed an HIV prevalence of $13.4 \%$ among prisoners, and a 2001-2002 sero-survey showed an HIV prevalence of $25.4 \%$ among all inmates in Bangkok, Thailand. ${ }^{19,20}$ In Eastern Europe, HIV prevalence among prisoners ranged from $0.03 \%$ in Hungary (1998) to $6 \%$ in Ukraine (1999), but figures kept increasing during the last few years. ${ }^{21}$

HIV-infected populations shift frequently in and out of correctional facilities. A 1997 report from the United Nations Programme on HIV/AIDS (UNAIDS) indicated that in Ireland, with a prison population of around 2,200, the annual turnover of prisoners was about 10,000 and the average sen- tence was 3-4 months. Out of the estimated 1,600 people in that country with HIV, some 300 to 500 had been through the prison system. ${ }^{13}$ In 1997, in the United States there were $>35,000$ prison inmates with HIV infection on any given day. In the same year, more than 150,000 of those released had HIV infection. It is estimated that, in 1997, 20\%$26 \%$ of all people living with HIV infection in the United States passed through a correctional facility. ${ }^{22}$ Having up to one fourth of the HIV-infected population passing through a single type of institution has enormous implications for a community's strategic HIV planning.

The epidemic of incarceration, which has paralleled the HIV epidemic in the United States, has resulted in the correctional system becoming an important source of health care for socially disadvantaged individuals, many of whom cycle in and out of prison and community settings. ${ }^{23}$ Correctional facilities represent a setting where many structural barriers to health care utilization are removed and access to care is (or should be) uniform. Thus, they offer unique opportunities to provide medical care, including ART. ${ }^{24}$

\section{ANTIRETROVIRAL TREATMENT IN CORRECTIONAL FACILITIES}

There are several issues to be considered when treating HIV+ prisoners with combination antiretroviral regimens. The main issues that will be discussed in this article are listed in the box titled "Relevant Issues on Antiretroviral Treatment in Correctional Facilities."

\section{Health Care for Prison Inmates}

Health in prison is a right guaranteed in international law, as well as in international rules, guidelines, and covenants including the Universal Declaration of Human Rights, the International Covenant on Economic, Social and Cultural Rights (Article 12), the International Covenant on Civil and Political Rights (Article 10.1), the United Nations' Basic Principles for the Treatment of Prisoners (Principles 5 and 9), and the Council of Europe's Committee of Ministers to Member States Concerning the Ethical and Organisational Aspects of Health Care in Prison (Recommendation 10). ${ }^{25}$ The right to health includes the right to medical treatment and to preventive measures and to stan- 


\section{Relevant Issues on Antiretroviral Treatment in Correctional Facilities}

- Basic health care for all prisoners

- Responsibility of health care in prisons

- Prison authorities

- Public health authorities

- HIV care for those infected

- Availability

- Provision

- Correctional facilities as entry point for HIV care (especially for marginalized populations)

- Sociocultural barriers: immigrants, language, education, ethnic minorities

- Policy and guidelines on antiretroviral treatment

- Formularies including antiretroviral drugs

- Availability and procurement of antiretroviral drugs

- Specialized HIV care

- HIV nurse

- HIV specialist part of the prison health staff

- HIV consultant

- Laboratory tests available

- Routine haematology and biochemistry

- Immunology

- Virology

- Antiretroviral resistance
- Adherence to antiretroviral treatment

- Administration of antiretroviral treatment

- DOT

- KOP/SAT

- Modified DOT

- Confidentiality

- Education of prison staff

- Peer support

- Continuity of care

- In/out: from community to prison to community

- Transfers within prison system

- Discharge planning

- Link with external/community health services

- Inmates' behavior

- ART refusal

- Hunger strike

- Therapy strike

- Co-morbidities (tuberculosis, HBV, HCV, mental illness, others)

- Prevention, diagnosis, and treatment

- Drug-drug interactions

- Access to experimental treatments available in the community

- Updated information on ART in prison setting

Note: $\mathrm{ART}=$ antiretroviral therapy; DOT = directly observed treatment; $\mathrm{KOP}=$ keep-on-person; HBV = hepatitis B virus; $\mathrm{HCV}=$ hepatitis $\mathrm{C}$ virus; HIV = human immunodeficiency virus; SAT = self-administered therapy.

dards of health care equivalent to those available in the community.

Thus, specific care for incarcerated HIV+ persons is a direct consequence of these principles. As it was stated in April 1996 by UNAIDS to the United Nations Commission on Human Rights at its 52nd session ${ }^{13}$ :

HIV / AIDS in prisons remains a difficult and controversial subject. [...] Often there are not enough resources to provide basic health care in prisons, much less HIV/AIDS programmes. Yet the situation is an urgent one. It involves the rights to health, security of person, equality before the law and freedom from inhuman and degrading treatment. It must be urgently addressed for the sake of health, rights and dignity of prisoners; for the sake of health and safety of prison staff; and for the sake of communities from which prisoners come and to which they return. With regard to effective HIV/ AIDS prevention and care programmes, prisoners have a right to be provided the basic standard of medical care available in the community.

\section{HIV/AIDS Care in Prison}

The very basic issue to be considered is the availability of health care in general and of HIV care specifically in the prison system. In this context, ART should be part of a comprehensive package of HIV care that should include counselling, testing, prevention of HIV transmission, availability of ARVs and of drugs for preventing and treating HIVrelated opportunistic infections, availability of HIV specialist physicians and nurses, and so on. ${ }^{21,25}$ 
Unfortunately, in many countries, health care for prisoners with HIV or AIDS is often nonexistent or minimal compared to what would be available outside.

Sometimes, the responsible authorities feel that isolating prisoners with HIV or AIDS is the answer to stopping the spread of HIV in prisons. This is probably not a rational answer to the problem.

Experience in a range of prison systems has shown that health care in prisons can be delivered more effectively by public health authorities than by prison management. This has the advantage of strengthening the link between health (including health education and counselling) in the community and health in prisons. ${ }^{26}$

Transferring control of prison health to public health authorities can be a structural change that could have a very great impact in the long run on HIV / AIDS care in prison. It is clear that in making such a move proper resources must be provided at the same time, and freedom of action of the new prison health authorities must be guaranteed. Some countries have already introduced such a change in prison health administration. Norway was one of the first. In France, where prison health was transferred to the Ministry of Health in 1994, a positive impact is already evident. Each prison in France is twinned with a public hospital. ${ }^{13}$ In Italy, integration between prison health authorities and centers for HIV care of the national public health system is in progress after a common decree of the responsible ministries in $1998 .{ }^{15}$

Members of the community who already lack adequate access to health care are incarcerated at a high rate; therefore, correctional institutions, where many structural barriers to health care use are removed and access to care is uniform, offer them an opportunity to access care for HIV infection. ${ }^{27}$ Different studies have demonstrated that most HIV + prisoners $(64 \%-67 \%)$ have been offered ART only or for the first time in correctional facilities. ${ }^{24,28}$ In one of these studies, HIV+ women were likely to use and engage in HIV-related primary care when prison-based health services were designed to meet their medical needs. The high proportion of female prisoners accepting ART in this context suggests that marginalized populations, which are overrepresented in the prison setting, are likely to accept treatment if it is offered in an appropriate context. ${ }^{28}$

Other difficulties may derive from inmates' so- ciocultural background; immigrants, ethnic minorities, and the poorly educated are largely represented among HIV+ prisoners. ${ }^{28}$ This may create linguistic, social, and cultural barriers that prevent inmates from fully accessing and benefiting from HIV care, including ART.

\section{Guidelines, Provision, and Availability of Antiretroviral Therapy}

In western countries where ARVs are easily available and affordable, many HIV+ inmates receive ART. In the 1998-1999 biennium in Texas (USA), almost 70\% of HIV+ inmates received ART at some time during detention, and almost $50 \%$ of them received HAART. ${ }^{29}$ In May 2002, 56.3\% of Italian HIV+ prisoners were receiving ART; $88.6 \%$ of them were receiving HAART. ${ }^{15}$

Provision of ART in correctional facilities requires that national (or at least international) policies and guidelines for the use of ARVs be followed. ${ }^{30,31}$ Because provision of health care is usually a basic right even for prisoners, no other special guidelines can be justified in this context.

Although prison inmates are one of the few groups of Americans whose access to health care is a right protected by US Supreme Court case law, ${ }^{32}$ treatment of HIV + prisoners has been criticized for years. ${ }^{27}$ After much debate, Departments of Corrections of the different states in the United States are gradually complying with the National Institutes of Health's (NIH) guidelines for the standard of care for HIV+ individuals. For example, in Connecticut, all inmates with known HIV infection should receive comprehensive HIV care from a board-certified infectious diseases specialist at regularly scheduled clinic visits, and ARVs available to inmates should include any US Food and Drug Administration-approved therapy. ${ }^{24,28}$ In Mississippi, a US Magistrate Judge ordered the state Department of Corrections to comply with the $\mathrm{NIH}^{\prime}$ s guidelines for the standard of care for HIV+ individuals. ${ }^{33}$ Actually, policy changes for correctional systems to include adoption of current HIV care standards and immediate evaluation for and access to HIV treatment upon entry into the institution have been advocated for years. ${ }^{34}$

The issue of treatment guidelines is also related to the availability of ARVs; the same drugs that are available outside the prison system should be available and regularly procured inside the prison 
system. ${ }^{21,25}$ Treatment guidelines without drugs do not work. Limited formularies may result in some medications not being available. In fact, patients cannot modify their ART depending on the available drugs in the local prison, but any change in treatment drugs should be guided by the attempt to provide the best possible treatment to the individual patient. Indeed, a report from Texas showed that one observed major barrier to patients receiving the right doses of the prescribed ARVs in prison was that medicine was not available. ${ }^{29}$ Even with the advent of effective combination therapy, the expansion of prison formularies often lagged. However, the current widespread availability of HAART in prison systems is responsible for the drastic decrease in AIDS mortality seen therein. For example, in the United States between 1995 and 2001, the number of AIDS-related deaths in state prisons decreased by $75 \%{ }^{18}$ The New York State Department of Corrections reported an AIDS-related death rate of 40.7 deaths per 10,000 inmates in 1990; in 1998, the rate had decreased to 6.1 deaths per 10,000 inmates, whereas death rates for other causes were stable. ${ }^{35}$

Another necessary component of comprehensive HIV / AIDS care that includes ART is the availability (inside or outside the correctional facility) of laboratory services for monitoring treatment efficacy (virologic and immunologic tests) and detecting drug-related toxicities (routine haematological and biochemical tests). ${ }^{21}$

\section{Specialist HIV Care}

Care of HIV + patients is increasingly becoming a subspecialty area of infectious diseases. Thus, in correctional facilities, care providers should be trained in HIV/AIDS care or there should be an HIV specialist physician and/or nurse. ${ }^{21,24}$ An HIV specialist should be consulted if the local provider lacks experience in treating HIV+ patients; otherwise possible consequences may be reduced or lack of benefit for treated inmates, undertreatment of side effects, or prescribing errors with HAART. ${ }^{36}$ The presence of an HIV specialist may also help in potentiating ART adherence. In a US study, correlates of medication adherence included the belief that the HIV doctor always understood the patients in prison (odds ratio $[\mathrm{OR}]=3.0$ ). ${ }^{28}$

Actually, in the prison setting, one can expect that patients' attitudes related to trust in medica- tions and the health care provider and satisfaction with health care in the correctional system may have particular relevance in the acceptance of, and adherence to, antiretroviral medications. ${ }^{28}$

\section{Adherence to Antiretroviral Therapy and Modalities of Administration}

A key aspect to obtaining the greatest benefits from ART is full adherence to the prescribed regimen. The special environment in the prison system can offer small and large obstacles, but also a few advantages. The areas of drug administration and adherence to ART should be carefully examined and specific solutions should be found to optimize adherence to treatment and to adapt strategies to the different country guidelines, kind and size of prison, and availability of staff and trained staff. The challenge is how to assist patients to fully adhere to antiretroviral regimens. This complex issue involves the entire health care team, in which nurses may play a key role. Although new drug treatments are designed to be easier to take, patients may still be nonadherent to even the simplest regimens.

The emerging problem of drug resistance is the unfortunate consequence of HIV medications being taken improperly or inconsistently. It has been reported that high viral loads in treated prisoners in the absence of drug-resistant mutations can be related to very poor treatment adherence. In contrast, detectable HIV viremia in patients carrying drug-resistant viruses may reflect treatment failure in adherent patients. A Spanish study showed that prisoners under ART presented a higher rate of virological failure in conjunction with an unexpected lower rate of drug resistance, which suggests that they were not taking their treatment. ${ }^{37}$ When present, resistance affected mainly drugs with low genetic barrier, such as lamivudine and nonnucleoside reverse transcriptase inhibitors (NNRTIs), and was a consequence of low treatment adherence in the incarcerated population. ${ }^{37}$

The good news from the prison system comes from a study in a prison population in Texas where overall self-reported rate of adherence to ART was high $(94.1 \%) .{ }^{29}$ In the same study, the most frequent reasons for missing doses of the study medication or medications were problems with dispensing or confusion $(15 \%)$, fatigue $(13.3 \%)$, and illness (12.4\%). However, when the reasons for missing 
doses were categorized as either "institutional" or "noninstitutional," inmates more often reported that the barriers to adherence were institutional. Some of the most common institutional barriers to receiving doses were that medicine was not available, the patient was not allowed to attend the medicine call, the patient did not want to go to the medication line, the patient was in "lockdown" (i.e., the prisoner was locked in his or her cell and was unable to receive the medication), the patient was moved to another cell, the patient was out of unit, or the study medication was on hold. Some of the most commonly reported noninstitutional barriers were that the patient felt fatigued or sleepy, the patient felt sick, the patient did not want to get out of bed, the patient felt depressed, the patient had a possible adverse event, or there was bad weather. ${ }^{29}$

A different study carried out in Connecticut (USA) showed that the most predictive factor associated with nonadherence in the multivariate analysis was the composite, side-effect variable, that is having experienced side effects from any ARV and having expressed willingness to stop medications if any side effects were to occur (11fold increase in nonadherence). Social isolation was associated with a 12-fold increased risk of nonadherence, and every step up in complexity of antiretroviral regimen (from monotherapy to dual nucleoside combination to protease inhibitor [PI]containing combinations) was associated with a threefold higher risk for nonadherence. ${ }^{24}$

Furthermore, it can be expected that in this setting attitudes related to trust in medications and the health care provider and satisfaction with health care in the correctional system may have particular relevance in the acceptance of, and adherence to, antiretroviral medications. Inmates' lack of trust in the correctional staff that dispenses many of these medications may further decrease adherence. In fact, trust in the prison health care system has been reported as being strongly correlated with drug adherence. ${ }^{28}$

The modality of ART administration can profoundly affect adherence to treatment. Directly observed administration of treatment (DOT) gives certainty of administration when drugs are given to the patient, and it has been studied in prison because of the peculiarities of this environment. Other strategies of ART administration in prisons include modified DOT, where patients receive their daily ARVs and swallow the morning dose in front of the staff and self-administer the others, and keep-on-person (KOP), where patients keep the full box of drugs with them in the cell (when refrigeration is not necessary) and self-administer ART. Any of the three strategies can be chosen, and they are sometimes used contemporarily in the same correctional facility with different patients, as it happens in our institution. Their advantages and disadvantages are reported in the box titled, "Advantages and Disadvantages of Different Modalities of Antiretroviral Therapy Administration."

A study of these aspects of ART showed that the degree of adherence was similar for patients who self-administered their medications and for those receiving DOT. ${ }^{24}$ In this case, one explanation could be the unique characteristics of the prison setting, where the structured environment, the organization of medication dispensation, and issues related to confidentiality contribute to similar rates of adherence. Alternatively, because inmates could choose how they take/receive their medications in this prison system, there may be some selection bias where the most motivated patients chose to self-administer medications. ${ }^{24}$ Actually, another study showed that among patients accepting ARVs, $62 \%$ were adherent to therapy. ${ }^{28}$ These proportions are as high as those found among HIV+ persons enrolled in primary care services linked to municipal hospitals, ${ }^{38,39}$ methadone maintenance programs, ${ }^{40,41}$ or research cohorts of injecting drug users $^{42}$ and are higher than those found for chronic illness-based medical treatments, such as asthma or hypertension.

Another example is the North Carolina Department of Corrections (USA) whose policy dictates that all PIs be administered by DOT, while other ARVs can be prescribed to be administered by DOT or by self-administered therapy (SAT; similar to $\mathrm{KOP})$, according to the preference of the clinician. ${ }^{43}$ A study performed in North Carolina showed that the extent of adherence to prescribed individual agents in a combination regimen did not appear to depend on the method of administration (SAT vs. DOT), although there was variability between the different measurement techniques. ${ }^{43}$ In addition, in this study, $68 \%$ of the participants responded that they would prefer to take medications on their own rather than having them provided via DOT. This could mean that motivated patients may be fully adherent even if not strictly 


\section{Advantages and Disadvantages of Different Modalities of Antiretroviral Therapy Administration}

Directly observed therapy (DOT) is the system in which the inmate goes directly to the medical unit or pharmacy for all medication doses and the nurse watches him/her swallowing medications. Administration of each dose for each patient should also be recorded. This system offers the advantage of more frequent interactions with the health care team, which allows for earlier identification of issues, concerns, and side effects. In general, there is greater adherence with this system that results in better control of HIV infection. Unfortunately, for some inmates, the need for frequent visits to the medical unit or pharmacy may be a barrier to treatment, particularly if they are housed at a distance from the unit or if they are involved in some working or studying activity. Another disadvantage to DOT is the potential loss of confidentiality as many inmates feel that the frequency of treatment and large number of pills taken will be clues that they are on treatment for HIV. However, in other settings, inmates receive their treatment from nurses when they are still locked in their cells, as hospitalized patients do in their rooms. These differences may depend on drug distribution policy in the country or in the single institution and on the daily load of drug distribution in the institution.

Modified DOT. In this case, antiretroviral therapy is distributed daily to prisoners by nurses. The nurses can watch or not watch the patient swallowing the morning dose of the prescribed medications. This approach carries most of the advantages of the other two strategies, but it is less time consuming for nurses than full DOT. On the other hand, it leaves at least one dose of medication under the inmate's full responsibility. Sometimes this strategy can be used for prisoners to shift from DOT to KOP, especially the ones who are going to be released soon.

Keep on person (KOP) or self-administered therapy (SAT) is the system that allows the inmates to keep their medications in their cells and take them independently. Monthly or weekly supplies are obtained at the medical unit or pharmacy. This system offers greater privacy and confidentiality regarding HIV status. The inmate also develops self-sufficiency in managing his/her medications that might facilitate improved adherence upon release. However, with less interaction with medical staff, it can be more difficult to identify problems with adherence or side effects.

supervised as in the case of DOT. However, the median level of adherence to ARV regimens in which $\geq 1$ medication was administered by DOT was suboptimal, as recorded by the most objective adherence measurements; more than one half of the participants had adherence rates that would not be expected to provide lasting viral suppression. ${ }^{43}$

An Italian study comparing DOT with modified DOT showed that the DOT group had significantly better virological and immunologic results than the other one. ${ }^{44}$ On the other side, a US study showed no differences in adherence to ART for patients receiving DOT and those who self-administered their medication. ${ }^{24}$

Discordant opinions exist about the introduction of the DOT strategy for ART administration in prisons. In fact, some authors observe that the applica- tion of DOT is resource intensive and may lead to a loss of confidentiality for the infected inmate, but others conclude that DOT may be an acceptable and feasible intervention for HIV+ prisoners, the cost of implementing DOT in this setting is low, and no additional staff is required to administer ART. ${ }^{43,44}$ The different conclusions may result from the different ARV combinations and fixed-dose combinations (FDCs) that are used, staff availability, and/or institutional organization. In particular, the use of anti-HIV FDCs (old and new) and regimens administered once daily (even if not yet studied in prison environment) may render DOT in correctional facilities less resource-consuming.

Notwithstanding results in favor of DOT, another observational study concluded that it was unclear whether DOT accounted for the difference in viro- 
logic outcomes observed in the study or whether people in prison had better adherence to drug therapy for other reasons, such as because they were receiving treatment for mental health disorders or because their illicit drug use was decreased. ${ }^{27}$ However, DOT strategy (or at least modified DOT) could be very useful for inmates in methadone maintenance treatment programs, especially for continuity of treatment after release. Actually, experiences of successful DOT anti-tuberculosis (TB) treatment linked to methadone maintenance treatment programs for ex-prisoners already exist. ${ }^{45}$

A justification for correctional health services policies that dictate DOT administration of ART could be the attempt not to waste funds, because ARVs account for a large portion of prison pharmaceutical budgets. ${ }^{27}$

Lack of health staff can be an obstacle to DOT strategy introduction/implementation and to adherence to ART. There are instances where medical staff was unavailable and correctional officers administered medications to inmates; in study interviews, inmates indicated a preference to receive medications only from medical personnel. ${ }^{43}$ Furthermore, correctional staff administering ART can cause a significant loss of confidentiality of HIV status, which can affect adherence.

To increase adherence to ART, it is also important to include the patient in the decision process regarding HIV treatment. Assessing the patient's biggest concerns about ART can be helpful in selecting a regimen she/he will more easily tolerate. Also, it is helpful to get a sense of the patient's daily routine; a regimen that can more easily fit into the patient's lifestyle will lead to improved adherence. Linking the dose to a regular part of the daily routine (such as breakfast or dinner) can also support adherence. This is relevant in prison, too. In fact, prisoners have different daily routines depending on residual length of stay, isolation, reason for conviction, and working and studying activities.

Offering positive reinforcement is an effective method of bolstering the inmate's confidence and adherence. Making a chart or graph of viral load and CD4 response to HAART, underscoring the relationship between adherence to therapy and success, and praising positive results can support patients in the task of adhering to treatment.

Peer support is an established and very useful strategy for ART adherence. It has also proved to be effective in prison populations. A study per- formed in a context where HIV support groups were regularly available to inmates showed that correlates of medication adherence included seeking advice or help from others when "down" (OR = 3.1). ${ }^{28}$ Furthermore, for this study population, adherence was strongly correlated with interpersonal trust. Such interpersonal trust was that found between the patient and physician and the trust in respected peers.

Another study that included four correctional facilities showed that women attended HIV support groups and showed greater trust in peers than men: $74 \%$ of the men "rarely" or "never" attended HIV support groups, compared with $51 \%$ of the women $(p<.001)$. Additionally, among those currently taking medications, nearly one third of the men and half the women reported being reminded daily to take their medication by a friend or cellmate $(32 \%$ vs. $50 \% ; p<.001) .{ }^{24}$ This may mean that clinical staff should explore further how to best provide support to patients who feel isolated. These individuals may require increased professional help from clinic nurses, mental health professionals, or other one-on-one counselors.

It can also be helpful to encourage inmates under ART to participate in groups and possibly consider becoming peer counsellors. Patients who do well with HAART often find it rewarding to "give back" to others in the same situation. ${ }^{36}$

In addition, it must be remembered that, even when ART is clinically required and correctly prescribed, patients can receive ARVs but not take them. Patients can stop taking medications to show that they can take care of themselves, while their clinical and viro-immunological conditions are worsening. In fact, prisoners in worsening physical conditions can request special benefits for health reasons, such as anticipated release, home or hospital arrest, or others. When such a situation is suspected, patients should be warned about the risks for their health and should be given a choice between ART discontinuation and DOT administration.

Another critical situation leading to nonadherence to ART is a hunger strike. It can easily happen and can be accompanied by therapy strike. In this latter case, the HIV nurse and the HIV specialist should counsel the inmate about risks for health and suggest that the inmate take at least full ART. In case of hunger strike, the prescribed regimen could be possibly modified to include only ARVs not requiring administration with food. 


\section{Choice of Antiretrovirals in Prison}

When treating HIV+ prisoners, a good knowledge of ART is necessary. These patients and the context of detention require specific attention, which is sometimes not sufficiently underscored in available treatment guidelines. Beyond standard recommendations on ART, there should be additional considerations when choosing an antiretroviral regimen for an HIV+ inmate. There should be a balance between the standard recommendations and the prison context.

Naturally, the choice of treatment would include simple regimens, possibly once or twice daily administration, limited food restrictions, and low pill burden. In addition, particular attention should be directed to co-morbidities and their treatments (chronic hepatitis B or C, tuberculosis, mental illness, etc.), methadone substitution treatment, and history of drug and/or alcohol abuse.

A series of advantages and disadvantages to be considered when choosing the components of ART regimens are reported in Table 1.

\section{Confidentiality}

A key issue that may drive inmates away from receiving adequate care and $\mathrm{ART}$ is the confidentiality of their HIV infection status. In a treatment study performed in prisons, a significant number of participants reported feeling socially isolated as a consequence of being $\mathrm{HIV}+$, and a large number of patients reported keeping their HIV infection hidden from other prison inmates. ${ }^{24}$ Another study on DOT showed that the majority of participants would rather not receive HIV-related medications by DOT; they frequently had to stand in line to receive DOT, which thereby compromised confidentiality. ${ }^{43}$ Actually, waiting in long lines to receive DOT medication may deter some inmates from starting or continuing therapy. Inmates may fear being labelled as HIV+-and therefore marginalized by other prisoners-if they are seen in line for medications several times a day; thus the use of DOT may result in a break in confidentiality. ${ }^{27}$

\section{Continuity of Care}

When treating HIV+ patients, the clinicians' target is to help them strictly adhere to their antiretroviral regimen even when they are no longer under the clinicians' direct responsibility. Because a large number of prisoners move in and out of the prison system, there should be some form of continuity of care from the community to the prison and back to the community. Actually, among patients who are incarcerated, transition between prison and the community is often associated with interruptions in care and treatment. ${ }^{46}$

Correctional facilities are sites for disadvantaged $\mathrm{HIV}+$ persons coming from the community to access care and sites for the introduction and maintenance of HIV-related care. Additionally, prisons constitute a critical opportunity for interventions ranging from peer support groups and HIV prevention programs to clinical trials. ${ }^{28}$ It is also known that although HIV+ inmates may achieve viral suppression in prison, these advances may be attenuated once they are released to the community. ${ }^{10}$

A number of studies and recommendations have highlighted the importance of the link between HIV specialists and correctional health care providers for ensuring that HIV+ patients have optimal care both inside prison and after release..$^{21,25,27,29}$ In terms of the prescription of ART in prisons, one study found that $72 \%$ of those eligible for treatment in the San Francisco jail were actually receiving therapy and that $71 \%$ followed medical advice and picked up medication at release. ${ }^{47}$

Programs that can ensure continuity of care for $\mathrm{HIV}+$ patients after release clearly need to be established and further evaluated..$^{48}$ Increased outreach to HIV+ IDUs recently released from prison also needs to be developed to ensure continuity of care. The integration of these strategies with adherence supports may allow, for example, more drug users to derive the full potential benefits of HAART. ${ }^{10}$

Prisoners should be considered part of society. Prisons, in fact, are not cut off from the world outside. As previously mentioned, most prisoners leave prison at some point to return to their community, some after only a short time inside, and some prisoners enter and leave prison many times. Since correctional facilities are only way stations for most accused persons, careful prison-discharge planning is key to preserving the health care advances made in prison. Attention to such issues as job placement, substance abuse treatment, housing, transportation, and child care enhances the likelihood that medical discharge planning will be effective. ${ }^{48}$ It may be helpful for prisoners to have face-to-face meetings with an outside health care 
Table 1. Reasons for choosing the components of antiretroviral regimens

\begin{tabular}{|c|c|}
\hline $\begin{array}{l}\text { Component of } \\
\text { antiretroviral regimens }\end{array}$ & Advantages \\
\hline Fixed-dose combinations & $\begin{array}{l}\text { Easier DOT } \\
\text { Low pill burden }\end{array}$ \\
\hline \multicolumn{2}{|l|}{$\begin{array}{l}\text { Didanosine, zalcitabine, } \\
\text { zidovudine }\end{array}$} \\
\hline \multicolumn{2}{|l|}{$\begin{array}{l}\text { Didanosine, zalcitabine } \\
\text { (less stavudine) }\end{array}$} \\
\hline Once-daily regimens & $\begin{array}{l}\text { Easier DOT and pharmacy } \\
\text { management }\end{array}$ \\
\hline \multicolumn{2}{|l|}{ Nevirapine } \\
\hline Efavirenz & $\begin{array}{l}\text { Less interactions with anti-TE } \\
\text { treatment (rifampin) }\end{array}$ \\
\hline NNRTIs & $\begin{array}{l}\text { Low pill burden (at least for } \\
\text { efavirenz and nevirapine) }\end{array}$ \\
\hline Protease inhibitors & $\begin{array}{l}\text { Ritonavir-boosted PI } \\
\text { associations may allow for } \\
\text { once-daily dosing; atazanavir } \\
\text { even without ritonavir- } \\
\text { boosting }\end{array}$ \\
\hline
\end{tabular}

NNRTIs and PIs

Disadvantages

Not all FDCs are included in first-line regimens in treatment guidelines

Increased bone marrow toxicity in those HCV co-infected when treated with ribavirin

Increased risk of pancreatitis in patients with alcohol abuse history

Increased risk of drug interactions when using ritonavir-boosted PI combinations

Increased toxicity in HBV or HCV co-infected

Increased risks of CNS toxicity in a population with high incidence of mental illness and drug abuse

Frequent risk of drug-drug interactions with concomitant therapies

- Frequent risk of drug-drug interactions with concomitant therapies

- Increased risk of drug interactions with ritonavir-boosted PI combinations

- Increased risk of hepatotoxicity

Metabolic interaction with methadone; dose adjustment of the latter is frequently required

Note: $\quad$ CNS = central nervous system; DOT = directly observed treatment; FDCs = fixed-dose combinations; HBV = hepatitis B virus; $\mathrm{HCV}=$ hepatitis $\mathrm{C}$ virus; NNRTIs = nonnucleoside reverse transcriptase inhibitors; PIs = protease inhibitors; TB = tuberculosis.

provider before discharge from prison. In jurisdictions where a great distance separates the correctional facility and the eventual home community, HIV programs could maintain prisoner follow-up by means of "telemedicine" or video conferencing or link inmates with faith-based communities, methadone maintenance programs, and job programs. However, at the minimum, released prisoners should be referred to HIV / AIDS care centers in their community; they should have written updated information on their health status and HIV treatment and enough ART (when necessary) for a few days while they get in touch with a new care provider. Good discharge planning, initiated well before prison release, reduced the rate of recidivism at 12 months among HIV+ Rhode Island (USA) women from $39 \%$ to $17 \% \%^{49}$ and reduced the rate of recidivism at 2 years for a Massachusetts (USA) jail cohort from $72 \%$ to $49 \% .{ }^{50}$ It has been speculated that these results could also apply to HIV care follow-up and regular continuation of ART; preliminary experiences show that this link between prison and community is feasible and is essential to obtain continuity of HIV care. ${ }^{27,51-53}$

Another issue is continuity of care within the prison system. Inmate facility transfers (because of overcrowding or of disciplinary, judicial, or personal reasons) or court dates may result in problems coordinating medical care and supplying 
needed medications in a timely fashion..$^{15,36,54}$ This causes the risk of treatment discontinuation for short or long periods of time. Furthermore, smaller prisons or jails with a minor load of HIV+ prisoners may not have stocks of ARVs and may lack some of the less frequently used drugs. Therefore procurement of drugs used for some prisoners may be difficult or slow, and ARV drugs could be unavailable for some time causing an unnecessary and unhealthy partial or total ART discontinuation. To reduce these difficulties, ARVs (up to 1-week prescription) could "follow" prisoners during transfers; this would allow the new prison sufficient time to procure the needed ARVs.

Another useful intervention in this regard may be educating security staff about the essential need for inmates to get their medications in a timely fashion and communicating with other facilities in advance of a transfer, thus eliminating or limiting missing doses. ${ }^{36}$

\section{Antiretroviral Drug Resistance}

Data on the rate of resistance to ARV drugs in incarcerated patients is scarce, but the recent availability of standardized ARVs resistance testing kits raises the issue of the indication of such tests in prisoners. Because HIV-infected inmates represent a large number of the total HIV+ population in Western countries, this information would be very useful. The few available studies reached different conclusions, probably depending on the different characteristics of the studied prison populations.

A Spanish study identified mutations associated with primary resistance to ARVs in $12.7 \%$ of the samples collected in 1999 and in 15\% of those collected in 2001. In ARV-experienced patients, however, drug resistance genotypes were more common, and overall they were recognized in $34.7 \%$ of samples collected in 1999 and in $58.7 \%$ of those collected in 2001. Therefore this study recommended resistance testing prior to starting ART. ${ }^{37}$ Another study performed in Spain concluded that the observed low prevalence of ARV resistance in treatment-naïve inmates suggested that performing resistance testing prior to starting ART in this population would not be necessary. ${ }^{55}$

In conclusion, resistance testing in HIV+ prisoners should probably follow the same guidelines used for the HIV+ population outside of prisons.

\section{Co-morbidities}

A critical issue for treated prisoners is the presence of important co-morbidities, such as chronic viral hepatitis, tuberculosis, and mental illness that often accompany HIV infection in this setting. ${ }^{26,27}$ Such concomitant clinical manifestations can make the choice of ARV combination difficult, because of possible drug interactions (especially PIs and NNRTIs with rifampin, benzodiazepines, and others), increased hepatotoxicity, haematological toxicity (e.g., ribavirin use in zidovudine-treated patients), reduced adherence to ART because of mental illness, and high pill load.

\section{Updates on Antiretroviral Treatment in Correctional Facilities}

Published studies are limited help in the search of the best regimen to be used in correctional facilities, because they are rather old and do not include the newer and often more tolerable ARVs. For example, the few studies on adherence to ART in prison settings evaluated stavudine, lamivudine, zidovudine, ritonavir and saquinavir, the triple combination of zidovudine, lamivudine, and abacavir (in fixeddose formulation or not), or unspecified combinations of the various classes..$^{24,43,44,56}$ Therefore, there is clearly the need for more recent studies on HIV+ inmates who are receiving current standard-of-care antiretroviral combinations.

In addition, inmates should have access to experimental anti-HIV treatments that are available in the community for two main reasons: their right to health includes advanced and experimental treatments when the ordinary ones are not sufficient, and inmates could enter the prison system already under experimental treatment and this treatment must not be discontinued. Furthermore, various recommendations (Europe Council, various Ministries of Public Health) exist on this issue, and a recent prison survey showed interest and availability of inmates to participate in clinical trials of experimental ART. ${ }^{15,25,28,57,58}$

\section{CONCLUSIONS}

Antiretroviral treatment provision in correctional facilities is feasible. Unfortunately, there are many obstacles that can reduce its positive impact on HIV+ prisoners' lives. Antiretroviral therapy in 
the prison context should be planned and guided at the country level, and solutions to the specific problems encountered in each institution can be found at the local level and then shared.

Addressing the relevant issues identified in this article and applying the suggested solutions with the flexibility to adapt them to the different contexts/ countries can be a way to improve access, provision, and adherence to ART in correctional facilities.

\section{REFERENCES}

1. Hogg RS, Ealt KV, Yip B, et al. Improved survival among HIV-infected individuals following initiation of antiretroviral therapy. JAMA. 1998;279:450-454.

2. Palella FJ Jr, Delaney KM, Moorman AC, et al. Declining morbidity and mortality among patients with advanced human immunodeficiency virus infection. HIV Outpatient Study Investigators. N Engl J Med. 1998;338:853-860.

3. Hogg RS, Yip B, Kully C, et al. Improved survival among HIV-infected patients after initiation of triple-drug antiretroviral regimens. CMAJ. 1999;160:659-665.

4. Floridia M, Massella M, Bucciardini R, et al. Hospitalizations and costs of treatment for protease inhibitor-based regimens in patients with very advanced HIV-infection (CD4 < 50/mm³). HIV Clin Trials. 2000;1:9-16.

5. Lavalle C, Aguilar JC, Pena F, Estrada-Aguilar JL, AvinaZubieta JA, Madrazo M. Reduction in hospitalization costs, morbidity, disability, and mortality in patients with AIDS treated with protease inhibitors. Arch Med Res. 2000;31:515-519.

6. Palepu A, Yip B, Miller C, et al. Factors associated with the response to antiretroviral therapy among HIV-infected patients with and without a history of injection drug use. AIDS. 2001;15:423-424.

7. Lucas GM, Chaisson RE, Moore RD. Highly active antiretroviral therapy in a large urban clinic: risk factors for virologic failure and adverse drug reactions. Ann Intern Med. 1999;131:81-87.

8. Moreno A, Perez-Elias MJ, Casado JL, et al. Long-term outcomes of protease inhibitor-based therapy in antiretroviral treatment-naive HIV-infected injection drug users on methadone maintenance programmes. AIDS. 2001;15:1068-1070.

9. Jensen-Fangel S, Pedersen L, Pedersen C, et al. The effect of race/ethnicity on the outcome of highly active antiretroviral therapy for human immunodeficiency virus type 1-infected patients. Clin Infect Dis. 2002;35:15411548.

10. Palepu A, Tyndall MW, Li K, et al. Alcohol use and incarceration adversely affect HIV-1 RNA suppression among injection drug users starting antiretroviral therapy. J Urban Health: Bull NY Acad Med. 2003;80(4):667-675.

11. Coetzee D, Hildebrand $K$, Boulle $A$, et al. Outcomes after two years of providing antiretroviral treatment in Khayelitsha, South Africa. AIDS. 2004;18(6):887-895.

12. Palombi L, Narciso P, Perno CF, et al. One year of HAART in Mozambique: survival, virological, and immunological re- sults of DREAM project in adults and children. In: Program and abstracts of the XI Conference on Retroviruses and Opportunistic Infections; February, 8-11, 2004; San Francisco, California. Abstract 148.

13. UNAIDS. Prisons and AIDS: UNAIDS Point of View. Geneva, Switzerland: Author; 1997.

14. Repubblica Italiana. Ministero della Giustizia. Dipartimento dell'Amministrazione Penitenziaria. Indagine nazionale sui detenuti tossicodipendenti e affetti da virus HIV; rilevamento al 31/12/2001. Rome, Italy: Ministry of Justice; 2002.

15. Commissione nazionale per la lotta contro l'AIDS e le altre malattie infettive emergenti e riemergenti. L'infezione da HIV nell'ambito degli istituti penitenziari. Rome, Italy: Ministero della Salute; December 18, 2003.

16. Long J, Allwright S, Barry J, et al. Prevalence of antibodies to hepatitis $B$, hepatitis $C$, and HIV and risk factors in entrants to Irish prisons: a national cross sectional survey. BMJ. 2001;323:1-6.

17. Maruschak LM. Bureau of Justice Statistics Bulletin: HIV in Prisons and Jails, 1999. Document NCJ 187456, 2001. Available at: http://www.ojp.usdoj.gov/bjs/abstract/ hivpj99.htm. Accessed September 20, 2004.

18. Maruschak LM. HIV in Prisons, 2001. Bureau of Justice Statistics, Bulletin. US Department of Justice, Office of Justice Programs; January 2004. Available at: http:// www.ojp.usdoj.gov/bjs/abstract/hivp01.htm. Accessed September 20, 2004.

19. Guimaraes T, Granato CF, Varella D, Ferraz ML, Castelo A, Kallas EG. High prevalence of hepatitis $C$ infection in a Brazilian prison: identification of risk factors for infection. Braz J Infect Dis. 2001;5(3):111-118.

20. Thaisri H, Lerwitworapong J, Vongsheree S, et al. HIV infection and risk factors among Bangkok prisoners, Thailand: a prospective cohort study. BMC Infect Dis. 2003;3:25.

21. WHO-EURO. HIV in Prisons. A Reader with Particular Relevance to the Newly Independent States. Copenhagen, Denmark: Author; 2001.

22. Hammett TM, Harmon MP, Rhodes W. The burden of infectious disease among inmates of and releasees from US correctional facilities, 1997. Am J Public Health. 2002;92:1789-1794.

23. Hammet, TM. Public Health/Corrections Collaborations: Prevention and Treatment of HIVIAIDS, STDs, and TB. Washington, DC: National Institute of Justice; 1998.

24. Altice FL, Mostashari F, Friedland GH. Trust and the acceptance of and adherence to antiretroviral therapy. $J$ Acquir Immune Defic Syndr. 2001;28:47-58.

25. Dublin declaration on HIV/AIDS in prisons in Europe and Central Asia: Prison health is public health. Dublin, Ireland. February 23, 2004. Available at: http://www.euro.who.int/ eprise/main/who/progs/HIPP/Home. Accessed August, 31 2004.

26. UNAIDS. Prisons and AIDS: UNAIDS Technical Update. Geneva, Switzerland: Author; 1997.

27. Spaulding A, Stephenson B, Macalino G, Ruby W, Clarke JG, Flanigan TP. Human immunodeficiency virus in correctional facilities: a review. Clin Infect Dis. 2002;35:305-312.

28. Mostashari F, Riley E, Selwyn PA, Altice FL. Acceptance and adherence with antiretroviral therapy among HIV-infected women in a correctional facility. J Acquir Immune 
Defic Syndr Hum Retrovirol. 1998;18(4):341-348.

29. Baillargeon J, Borucki MJ, Zepeda S, Jenson HB, Leach CT. Antiretroviral prescribing patterns in the Texas prison system. Clin Infect Dis. 2000;31:1476-1481.

30. World Health Organization. Scaling Up Antiretroviral Therapy in Resource-Limited Settings: Guidelines for a Public Health Approach, 2003 revision. Geneva, Switzerland: WHO; December 2003.

31. Department of Health and Human Services. Guidelines for the Use of Antiretroviral Agents in HIV-1-Infected Adults and Adolescents. March 23, 2004. Available at: http:// www.aidsinfo.nih.gov//guidelines/adult/AA_032304.pdf. Accessed September 20, 2004.

32. Estelle v. Gamble, 429 US 97 (Supreme Court 1976); USA.

33. Judge says prison must obey NIH treatment guidelines. National Institute of Health. AIDS Policy Law. 1999;14(14):1-8.

34. Frank L. Prisons and public health: emerging issues in HIV treatment adherence. J Assoc Nurses AIDS Care. 1999;10(6):24-32.

35. Griffin MM, Ryan JG, Briscoe VS, Shadle KM. Effects of incarceration on HIV-infected individuals. J Natl Med Assoc. 1996;88:639-644.

36. Hubbard M., Piliero PJ, Moehs CJ, Battaglioli-DeNero A, eds. Nursing Care of the HIV-Infected Inmate Learning Module 3: Adherence \& Resistance. Albany, NY: Albany Medical Center Hospital; 2003.

37. Gallego O, Corral A, de Mendoza C, González-Lahoz Juan, Soriano V. High rate of resistance to antiretroviral drugs among HIV-infected prison inmates. Med Sci Monit. 2003;9(6):CR269-273.

38. Samet JH, Libman H, Steger KA, et al. Compliance with zidovudine therapy in patients infected with human immunodeficiency virus, type 1: a cross-sectional study in a municipal hospital clinic. Am J Med. 1992;92:495-501.

39. Muma RD, Ross MW, Parcel GS, Pollard RB. Zidovudine adherence among individuals with HIV infection. AIDS Care. 1995;7:439-447.

40. O'Connor PG, Molde S, Henry S, Shockcor WT, Schottenfeld RS. Human immunodeficiency virus infection in injection drug users: a model for primary care. Am J Med. 1992;93:382-386.

41. Selwyn PA, Budner NS, Wasserman WC, Arno PS. Utilization of on-site primary care services by HIV-seropositive and seronegative drug users in a methadone maintenance program. Public Health Rep. 1993;108:492-500.

42. Solomon L, Vlahov D, Astemborski J, Galai N, Graham $\mathrm{NMH}$, Nelson KE. Factors associated with initiation of zidovudine in a cohort of injection drug users. J Drug Issues. 1995;25:225-233.

43. Wohl DA, Stephenson BL, Golin CE, et al. Adherence to directly observed antiretroviral therapy among human immunodeficiency virus-infected prison inmates. Clin Infect Dis. 2003;36:1572-1576.

44. Babudieri S, D'Offizi GP, Carbonara S, Starnini G. Directly observed therapy to treat HIV infection in prisoners. JAMA. 2000;284(2):179-180.

45. Marco A, Cayla JA, Serra M, et al. Predictors of adherence to tuberculosis treatment in a supervised therapy programme for prisoners before and after release. Study
Group of Adherence to Tuberculosis Treatment of Prisoners. Eur Respir J. 1998;12(4):967-971.

46. Wood E, Montaner JSG, Bangsberg DR, et al. Expanding access to HIV antiretroviral therapy among marginalized populations in the developed world. AIDS. 2003;17(17): 2419-2427.

47. White MC, Mehrotra A, Menendez E, Estes M, Goldenson J, Tulsky JP. Jail inmates and HIV care: provision of antiretroviral therapy and Pneumocystis carinii pneumonia prophylaxis. Int J STD AIDS. 2001;12(6):380-385.

48. Kim JY, Rich J, Zeiler S, et al. Successful community follow-up and reduced recidivism of HIV positive women prisoners. J Correctional Health Care. 1997;4:1-9.

49. Flanigan TP, Kim JY, Zierler S, Rich JD, Vigilante K, BuryMaynard D. A prison release program for HIV-positive women: linking them to health services and community follow-up. Am J Public Health. 1996;86:886-887.

50. Skolnick AA. Correctional and community health care collaborations. JAMA. 1998;279:98-99.

51. Wohl DA, Stephenson BL, Strauss R, et al. Access to HIV care and antiretroviral therapy following release from prison. In: Program and abstract of XI Conference on Retroviruses and Opportunistic Infections; February, 811, 2004; San Francisco, California. Abstract 859.

52. Howard TR, Campbell WA. Positive tools for HIV+ prisoners. In: Program and abstract of XV International AIDS Conference; July, 11-16, 2004; Bangkok, Thailand. Abstract number: WePeE6856.

53. Kennedy SS, Hammett TM, Braithwaite R, Arriola KRJ. Improving access to and utilization of health and social services for HIV-infected jail and prison releasees: evaluation results from the Corrections Demonstration Project funded by the Centers For Disease Control and Prevention (CDC) and Health Resources and Services Administration (HRSA). In: Program and abstract of XV International AIDS Conference; July, 11-16, 2004; Bangkok, Thailand. Abstract ThPeE7996.

54. Babudieri S, Starnini G, Brunetti B, et al. HIV e infezioni correlate negli Istituti Penitenziari Italiani: note di epidemiologia e di organizzazione sanitaria. Ann Ist Super Sanità. 2003;39(2):251-257.

55. García-Guerrero J, Herrero A, Bedia M, Araújo R, Castellano JC. Grupo de Estudio REPRICOVA. Resistencias primarias de $\mathrm{VIH}$ en una población penitenciaria. Estudio REPRICOVA-2. Enferm Infecc Microbiol Clin. 2004;22:29-31.

56. Kirkland LR, Fischl MA, Tashima KT, et al. for the NZTA4007 Study Team. Response to LamivudineZidovudine plus Abacavir twice daily in antiretroviral-naive, incarcerated patients with HIV infection taking directly observed treatment. Clin Infect Dis. 2002;34:511-518.

57. Europe Council. Recommandation N.R. (93) 6 du Comité des Ministres aux Etats membres concernant les aspects pénitentiaires et criminologiques du contrôle des maladies transmissible et notamment du SIDA, et les problèmes connexes de santé en prison. 1993.

58. Palmiere $\mathrm{C}$, Toscanini $\mathrm{F}$. La normativa italiana in materia di AIDS. Istituto Italiano di Medicina Sociale. Rome, Italy; 2004. 